\title{
Effects of Pt Seedlayer and Ar Pressure on Magnetic and Structural Properties of Sputtered CoNi/Pt Multilayers
}

\author{
Q. Meng, P. de Haan, W. P. van Drent, J. C. Lodder and Th. J. A. Popma \\ MESA Research Institute, University of Twente, P. O. Box 217, 7500 AE, Enschede, The Netherlands
}

\begin{abstract}
CoNi/Pt multilayers were prepared by magnetron sputtering using Ar gas. Effects of Pt seedlayer and Ar sputtering pressure on magnetic and structural properties are investigated. Microstructures of multilayers were analysed using XRD and TEM. It was found that perpendicular magnetic anisotropy and coercivity increase with increasing either the thickness of $\mathrm{Pt}$ seedlayer or Ar pressure. The causes of increases in perpendicular anisotropy and coercivity are discussed in relation to the interface roughness, the curvature of layers and the columnar structures.
\end{abstract}

\section{INTRODUCTION}

It has been reported that $\mathrm{CoNi} / \mathrm{Pt}$ multilayers provide high write sensitivity and high number of write/erase cycles for MO recording due to their lower Curie temperature compared with $\mathrm{Co} / \mathrm{Pt}$ multilayer media [1]. We previously reported upon magnetic properties of CoNi/Pt multilayers, especially the dependence of Curie temperature on $\mathrm{CoNi}$ and $\mathrm{Pt}$ layer thickness [2]. The properties of thermomagnetic written domains in CoNi/Pt multilayers have been investigated [3]. In this paper, the magnetic properties, especially the perpendicular magnetic anisotropy and the coercivity will be discussed as a function of $\mathrm{Pt}$ seedlayer thickness and $\mathrm{Ar}$ sputtering pressure.

\section{EXPERIMENTAI}

$\mathrm{CoNi} / \mathrm{Pt}$ multilayers were deposited on $\mathrm{Si}(001)$ substrates by magnetron sputtering using Ar gas. The base pressure was lower than $5 \times 10^{-8}$ mbar. The distance between the target and the substrate was $10 \mathrm{~cm}$. There was neither heating nor cooling applied to the substrate during the deposition. The Ar pressure and the electric power were kept constant during the deposition. A Co- $\mathrm{Ni}$ composite target or a $\mathrm{Co}_{0.5} \mathrm{Ni}_{0.5}$ alloy target was used for the deposition of the CoNi layer with a rf power of $100 \mathrm{w}$ or $50 \mathrm{w}$, respectively. A de-power of $50 \mathrm{w}$ was used for Pt sputtering. The composition of the CoNi layer was $50: 50$ at $\%$ as measured by EDX (Energy Dispersive X-ray) and XRF (X-ray Fluorescence). The multilayer structure was designed as Si-substrate/Ptseedlayer $/(\mathrm{CoNi} / \mathrm{Pt}) \times n$. Individual layer thickness $t_{\mathrm{CoNi}}$ and $t_{\mathrm{Pt}}$ were estimated from the product of the deposition time and deposition rate and confirmed by low and high angle XRD (X-ray diffraction) measurements. Saturation magnetisation $M_{\mathrm{s}}$ and coercivity, $H_{\mathrm{c}}$ were obtained from perpendicular

Manuscript received December 4, 1995

Q. Meng, mng@el.utwente.nl, fax -31-53-4309547; phone -31-534894436; J. C. Lodder, J.C.Lodder@el.utwente.nl, fax -31-53-4309547; phone $-31-53-4892750$.

This work was supported in part by the Foundation for Fundamental Research on Matter (FOM) of The Netherlands.
VSM loops. Effective perpendicular anisotropy constant, $\mathrm{K}_{\text {eff }}$ (including the demagnetisation energy) was measured using a torque magnetometer.

\section{RESULTS AND DISCUSSION}

Fig. 1 shows a typical microstructure of a $\mathrm{CoNi} / \mathrm{Pt}$ multilayer on Si substrate. The curvature of the layers and the columnar structures become clear with the film growing. The roughness of the film surface and interfaces as shown in this image will be used in the following discussion with regard to XRD patterns. Low and high angle XRD patterns demonstrate a well defined periodic modulation of the chemical composition in multilayers and a fcc-(111) orientation along the film growth direction as shown in Fig. 2 and Fig.4.

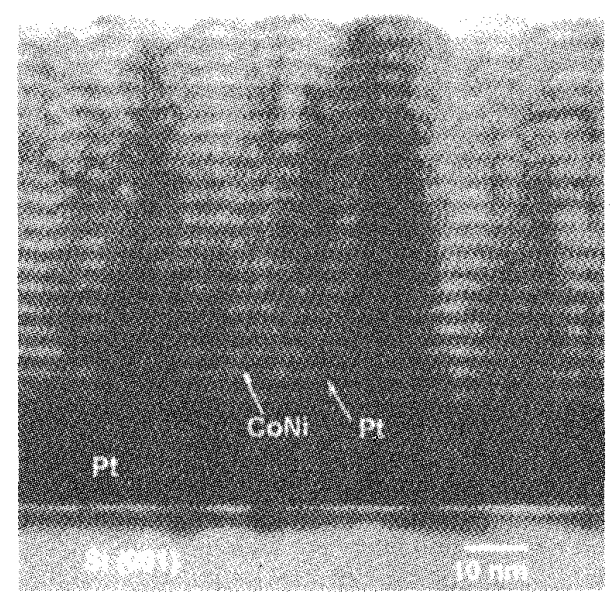

Fig. 1. A typical cross-sectional TEM image of a $\mathrm{Co}_{0.5} \mathrm{Ni}_{0.5} / \mathrm{Pt}$ multilayer deposited at $\mathrm{P}_{\mathrm{Ar}}=1.6 \times 10^{-2}$ mbar with a composition of $\mathrm{Si} / 24 \mathrm{~nm} \mathrm{Pt} /(3.8 \mathrm{~nm}$ CoNi $1.5 \mathrm{~nm} \mathrm{Pt}) \times 17$.

\section{A. Effects of Pt Seedlayer}

One series of $\mathrm{Co}_{0.5} \mathrm{Ni}_{0.5} / \mathrm{Pt}$ multilayers was deposited with varying the $\mathrm{Pt}$ seedlayer thickness and the number of $\mathrm{CoNi} / \mathrm{Pt}$ bilayers. The designed thickness and magnetic characteristics are listed in Table I. The low and high angle XRD patterns of this series are shown in Fig. 2. There is no fcc-(111) peak of the Pt in the patterns of the samples $A$ and $B$ because their "Pt seedlayers" are only about $1 \mathrm{~nm}$. The intensity of the first order periodic modulation peak $(\mathrm{m}=1)$ and $\mathrm{CoNi} / \mathrm{Pt}$ crystalline main peak $(n=0)$ of the sample $A$ are higher than $B$ because of more bilayers in $A$. The high angle patterns of the samples $\mathrm{C}$ and $\mathrm{D}$ display the fcc-(111) peak of the $\mathrm{Pt}$ 
TABLE I

Designed THICKNESS AND Magnetic Characteristics of CoNi/Pt MultLlayers

\begin{tabular}{|c|c|c|c|c|c|c|c|c|c|c|}
\hline Sample & $\begin{array}{c}\mathrm{Ar} \\
\text { pressure } \\
\left(10^{-2} \mathrm{mbar}\right)\end{array}$ & $\begin{array}{c}P t \\
\text { seedlayer } \\
(\AA)\end{array}$ & $\begin{array}{c}\mathrm{CoNi} \\
\text { layer } \\
(\AA)\end{array}$ & $\begin{array}{c}\mathrm{Pt} \\
\text { layer } \\
(\AA)\end{array}$ & $\begin{array}{c}\text { Number of } \\
\text { bilayer }\end{array}$ & $\begin{array}{c}\text { Total } \\
\text { thickness } \\
(\AA)\end{array}$ & $\begin{array}{c}\mathrm{M}_{\mathrm{s}} \\
(\mathrm{CoNi} / \mathrm{Pt}) \\
(\mathrm{kA} / \mathrm{m})\end{array}$ & $\mathrm{M}_{\mathrm{r}} / \mathrm{M}_{\mathrm{s}}$ & $\begin{array}{c}\mathrm{H}_{\mathrm{c}}(\perp) \\
(\mathrm{kA} / \mathrm{m})\end{array}$ & $\begin{array}{c}\mathrm{K}_{\mathrm{eff}} \\
(\mathrm{CoNi} / \mathrm{Pt}) \\
\left(\mathrm{kJ} / \mathrm{m}^{3}\right)\end{array}$ \\
\hline A & 1.6 & 10 & 5.8 & 10 & 33 & 531 & 305 & 0.8 & 20 & 135 \\
\hline $\mathrm{C}$ & 1.6 & 264 & 5.8 & 10 & 17 & 533 & 288 & 1 & 46 & 165 \\
\hline D & 1.6 & 528 & 5.8 & 10 & 17 & 797 & 307 & 1 & 55 & 165 \\
\hline
\end{tabular}

because of their thicker Pt seedlayers. With those enhanced $\mathrm{Pt}$ peaks, the intensities of main peaks $(\mathrm{n}=0)$ of the CoNi/Pt increase and their satellite peaks $(n=-1)$ become visible. This implies that the degree of fcc-(111) texture is enhanced by the thicker $\mathrm{Pt}$ seedlayer. However, with increasing $\mathrm{Pt}$ seedlayer thickness, the intensities of " $\mathrm{m}=1$ " peaks of $\mathrm{C}$ and $\mathrm{D}$ in the low angle patterns decrease, which indicates that interfaces between $\mathrm{CoNi}$ and $\mathrm{Pt}$ layers become rougher due to the curvature of the layers and the columnar structures because of the thicker films (see Fig. 1). The oscillation peaks before the " $\mathrm{m}=1$ " peak are caused by the total film thickness including the Pt seedlayer. The difference in the amplitude of those peaks gives an indication of the difference

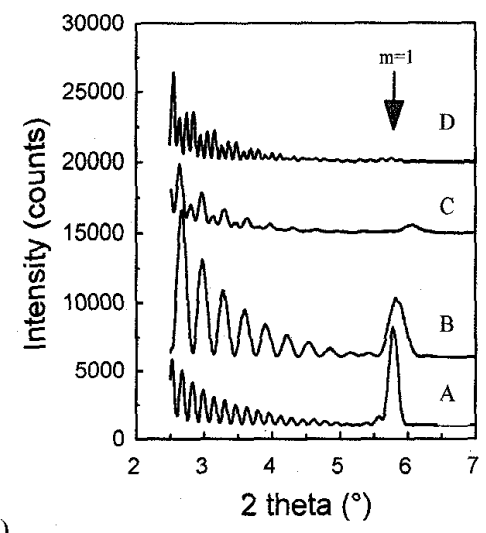

(a)

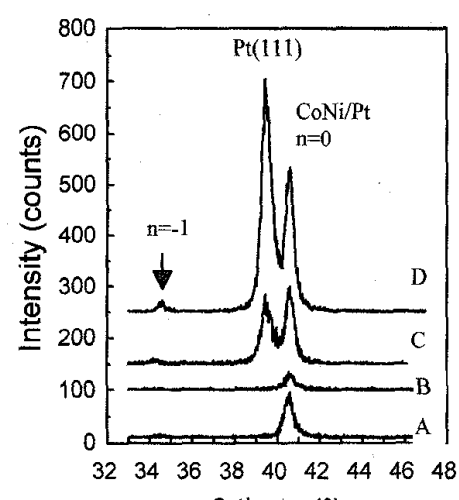

(b)

2 theta $\left({ }^{\circ}\right)$

Fig. 2. XRD patterns of CoNi/Pt multilayers as indicated in Table I. " $\mathrm{m}=1$ " indicates the first order periodic modulation peaks; " $n=0$ " the $\mathrm{CoNi} / \mathrm{Pt}$ main peaks and " $n=-1$ " the satellite peaks. The measurement conditions were the same for these four samples. $(\lambda=1.5415 \AA)$ in the roughness or the flatness of the film surface. Their surface roughness can be determined in an order as $\mathrm{B}<\mathrm{A}<\mathrm{C}<\mathrm{D}$, which has been confirmed by AFM (Atomic Force Microscopy).

As shown in Table $\mathrm{I}$, the perpendicular anisotropy, $\mathrm{K}_{\mathrm{eff}}$ and the coercivity, $\mathrm{H}_{\mathrm{c}}$ increases with increasing $\mathrm{Pt}$ seedlayer thickness. This is attributed to the enhanced fcc-(111) texture and the columnar structures. The enhancement of the fcc-(111) texture results in an increased $K_{\text {eff. }}$ The increased $\mathrm{K}_{\mathrm{eff}}$ contributes to the increase in $\mathrm{H}_{\mathrm{c}}$ and improves the squareness ratio $M_{r} / M_{s}$, which is clearly revealed by the difference in $M_{r} / M_{s}$ and $K_{\text {eff }}$ between the samples $A$ and $B$. The difference of their $\mathrm{K}_{\mathrm{eff}}$ is attributed to the difference in their interfacial roughness. The increase in $\mathrm{H}_{c}$ is also attributed to the columnar boundaries according to the mechanism of domain wall pinning $[4,5]$. In Table $\mathrm{I}$, the magnetisation $M_{s}$ of $C$ is smaller because the real CoNi thickness could be thinner than designed thickness as shown by the position of its " $m=1$ " peak at the low-angle XRD pattern (see Fig. 2 (a)).

\section{B. Effects of Ar Pressure}

Fig. 3 shows perpendicular VSM loops of a series of $\mathrm{Co}_{0.5} \mathrm{Ni}_{0.5} / \mathrm{Pt}$ multilayers deposited at different Ar pressures. It shows that $\mathrm{H}_{\mathrm{c}}$ increases with increasing Ar pressure. At $4.0 \times 10^{-2}$ mbar, a maximum $H_{c}$ of about $100 \mathrm{kA} / \mathrm{m}$ is achieved. With increasing $\mathrm{P}_{\mathrm{Ar}}$ up to $4.8 \times 10^{-2} \mathrm{mbar}, \mathrm{H}_{\mathrm{c}}$ and $M_{r} / M_{s}$ degrade. Fig. 4 shows low and high angle XRD patterns of this series. As can be seen, intensities of the main peak $(n=0)$ and satellite peak $(m=1)$ decrease with increasing $\mathrm{P}_{\text {Ar. }}$ This indicates that the degree of fcc-(111) texture and the sharpness of interfaces degrade due to the higher $P_{A r}$, which implies that the perpendicular anisotropy, $\mathrm{K}_{\text {eff }}$ might decrease. However, $\mathrm{K}_{\text {eff }}$ does not decreases but increases from 77 to 124 and $145 \mathrm{~kJ} / \mathrm{m}^{3}$ (per unit $\mathrm{CoNi} / \mathrm{Pt}$ volume) with increasing $\mathrm{P}_{\mathrm{AI}}$ from 0.8 to 1.6 and $4.0 \times 10^{-2} \mathrm{mbar}$, respectively and then decreases to $99 \mathrm{~kJ} / \mathrm{m}^{3}$ at $4.8 \times 10^{-2}$ mbar. This agrees quite well with the variation in $H_{c}$ and $M_{r} / M_{s}$ as shown in Fig. 3. In order to understand this unexpected increased $\mathrm{K}_{\mathrm{eff}}$, the microstructure of a $\mathrm{Co}_{0.5} \mathrm{Ni}_{0.5} / \mathrm{Pt}$ multilayer deposited at $4.0 \times 10^{-2}$ mbar was investigated using TEM. The cross sectional TEM image shows that the interfaces between the CoNi and Pt layers still exist within the columns and the curvature of the layers is enhanced, which could contribute to the increased $\mathrm{K}_{\mathrm{cff}}$ because of the enhanced strain anisotropy at the interfaces. 
(a)

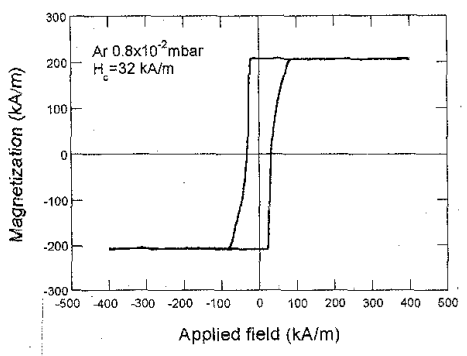

(b)
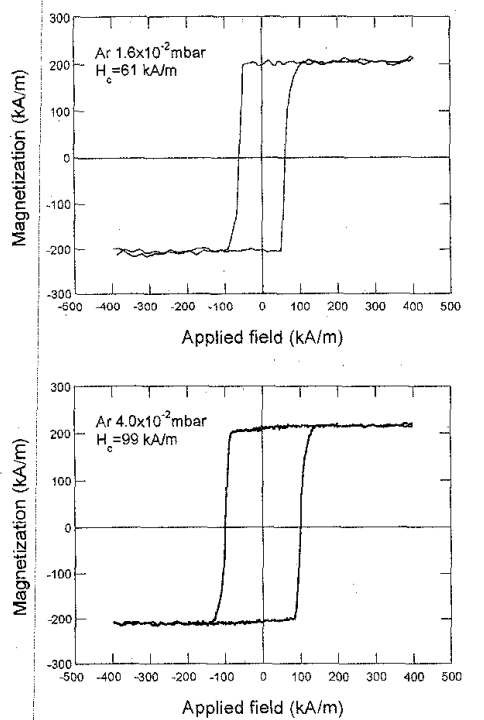

(c)

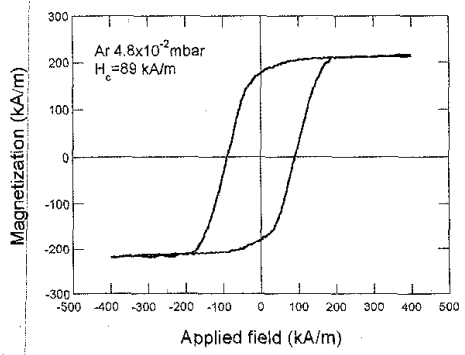

Fig. 3. Perpendicular VSM loops of CoNi/Pt multilayers deposited at different Ar pressures as indicated in the figure. The composition is $\mathrm{Si} / 24$ $n m$ Pt/(0.5 nm CoNi $/ 1.5 \mathrm{~nm} \mathrm{Pt}) \times 17$.

The roughness determined by XRD gives an indication of the interfacial roughness over a large area including many columns. It does not provide any information about the local interfaces within the columns because the column size is only about 10 or $20 \mathrm{~nm}$. However, when $\mathrm{P}_{\mathrm{A} i \mathrm{~T}}$ was too high $\left(>4.8 \times 10^{-2} \mathrm{mbar}\right)$, the interfaces and the crystalline structure of layers became very poor so that $\mathrm{K}_{\mathrm{eff}}$ and $\mathrm{H}_{\mathrm{c}}$ were reduced as shown in Fig. 3 (d).

Furthermore, the plane-view TEM image of a $\mathrm{Co} / \mathrm{Pt}$ multilayer which was deposited at the higher $\mathrm{P}_{\mathrm{Ar}}\left(4.0 \times 10^{-2}\right.$ mbar) shows the large voids at the grain boundaries [3]. The voids can act as domain wall pinning sites which contribute to the larger $\mathrm{H}_{c}[6]$. However, the large voids could cause the readout noise which is not desirable for MO application.

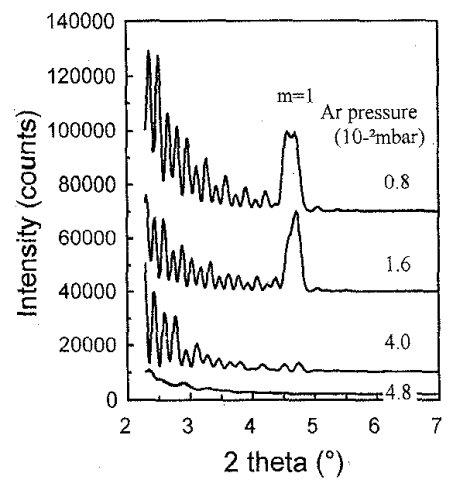

(a)

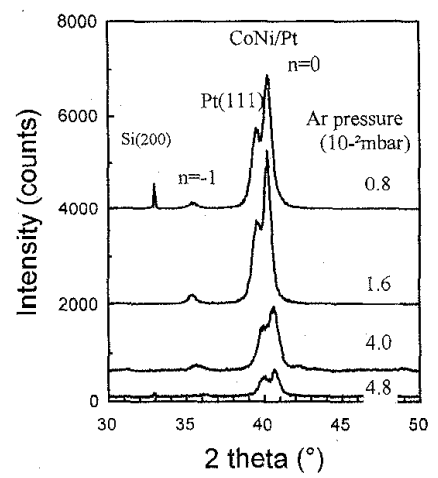

Fig. 4. XRD patterns of CoNi/Pt multilayers as indicated in Fig. 3. " $\mathrm{m}=1$ " " $n=0$ " and " $n=-1$ " have the same meaning as shown in Fig. 2 , The measurements conditions for these four samples were the same.

\section{CONCLUSION}

Perpendicular magnetic anisotropy and coercivity of $\mathrm{CoNi} / \mathrm{Pt}$ multilayers can be enhanced by using thicker $\mathrm{Pt}$ seedlayer and higher Ar sputtering pressure. The increase in perpendicular anisotropy at higher Ar pressures is attributed to the enhanced strain anisotropy at the interfaces because of the enhanced curvature of the layers. The increase in $\mathrm{H}_{\mathrm{c}}$ is attributed to the columnar structure and the voids due to the domain wall pinning.

\section{REFERENCES}

[1] S. Hashimoto, A. Maesaka, K. Fujimoto, and K. Bessho, "Magnetooptical application of $\mathrm{Co} / \mathrm{Pt}$ multilayers," J. Magn. Magn. Mater., 121 (1993) 471

[2] Q. Meng, W. P. van Drent, J. C. Lodder, and Th. J. A. Popma, "Curie temperature dependence of magnetic properties of $\mathrm{CoNi} / \mathrm{Pt}$ multilayer films," Dig. MML'95, p. 267. 1995. [to be published in J. Magn. Magn. Mater., 1996.]

[3] Q. Meng, D. M. Donnet, P. J. A. van Schendel, J. C. Lodder, and Th. J. A. Popma, Dig. MORIS'96, Noordwijkerhout, The Netherlands, April 29 May 2, 1996. [to be published in J. Magn. Soc. Jpn., 1996.]

[4] T. Suzuki, H. Notarys, D. C. Dobbertin, C-J. Lin, D. Weller, D. C. Miller and G. Gorman, "Coercivity mechanism and microstructure of $\mathrm{Co} / \mathrm{Pt}$ multilayers," IEEE Trans. Magn, 28 (1992) 2754.

[5] T. K. Hatwar and C. F. Brucher, "Coercivity enhancement of Co/Pt superlattices through underlayer microstructure modification," IEEE Trans. Magn. 31 (1995) 3256

[6] P. F. Carcia and W. B. Zeper, "Sputtered Pt/Co multilayers for magnetooptical recording," IEEE Trans. Magn, 26 (1990) 1703. 